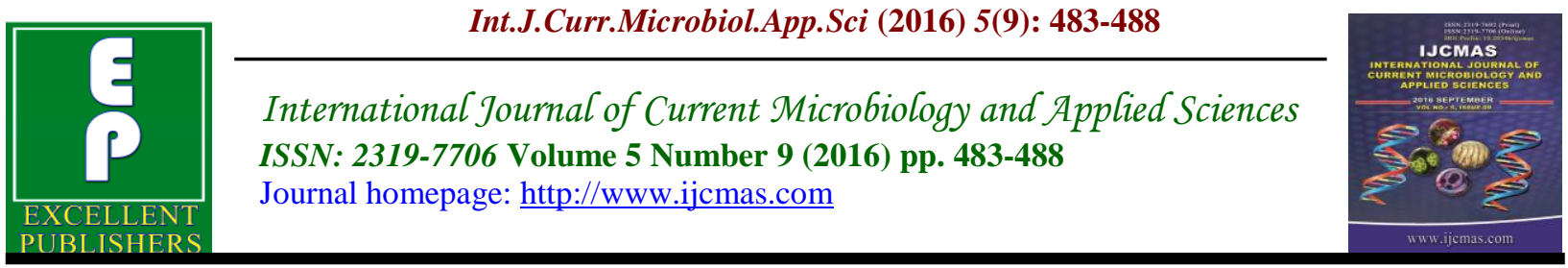

Original Research Article

http://dx.doi.org/10.20546/ijcmas.2016.509.053

\title{
Temperature Threshold and Thermal Constant of Dacus frontalis (Beker) (Order: Diptera: Tephritidae) on Three Cucurbit Hosts
}

\author{
Hasanain Yosuf Al-Shalchi ${ }^{1 *}$ and Redha S. Al Jorany ${ }^{2}$ \\ ${ }^{1}$ State of Agricultural research-Ministry of Agriculture, Iraq \\ ${ }^{2}$ Department of Plant Protection, College of Agriculture, University of Baghdad, Iraq \\ *Corresponding author
}

Keywords

Dacus frontalis, development

period, zucchini, cucumber, thermal constant.

\section{Article Info}

Accepted:

20 August 2016

Available Online:

10 September 2016

\section{A B S T R A C T}

The aim of this work was to determination of the threshold temperature and the required degree days for development represent the fundamental base for prediction of phenology of the insect annually as well as integrated with the other methods. The time needed for $50 \%$ of individuals to achieve development from egg stage to adult stage was recorded at the following constant temperatures: 15, 20, 25, and 30 $\pm 1 \mathrm{C}^{\circ}$. The results revealed that there are significant differences of development periods of Dacus frontalis at the different temperatures and hosts, the shortest period of development to adult's stage was at the $30^{\circ} \mathrm{C}$ on Zucchini reached 15.207 days and the longest period was at the $15^{\circ} \mathrm{C}$ on Cucumber. The threshold temperatures were 11.7, 11.47 and 12.8 for crop Armenian cucumber, cucumber and Zucchini respectively. This is the first work on threshold temperature and development periods of $D$. frontalis.

\section{Introduction}

The fruit flies are one of the most important insect pest groups of horticulture production and export throughout the world. The economical loss by this group of insect is about 30-70\% of yield (Gillani et al., 2002; Royer and Hancock, 2012).

Over 4000 species that occur worldwide, 700 species belong to Sub family: Dacine and from most important genus are Dacus and Bactrocera which have about 50 species are regarded as major pest species on Cuccurbitaceaein addition to the other wild species like Citrullus colocynthuss chard and Luffa aegytiaca Miller (Mahdi, 2000).
In taxonomical study for Tephritidae species in Iraqi provinces (Al Safar, 2011) was recorded three species attack cucurbit plants in different area in Iraq, which are Dacus ciliatus Loew, Dacus frontalis Becker and Myiopardalis pardalina (Bigot) (Al saffar, 2011).

D. frontalis distributed in most Africa countries, Yaman, Saudi arabia and Jordan: attacks all cucurbit fruits causes loss in yield about $20-100 \%$ in some regions (Ekesi and Billah, 2007; Ba-Angood, 1977; El-sabah and Fetoh, 2010) The most dominant species is Dacus frontalis Becker in iraq (Al Jorani, 2013). 
D. frontalis is qualitative pest on cucurbit fruits causes economic lose annually in Iraq. Cucurbita pepo Zucchini (summer squash) and Cucumis sativus L (Cucumber) have been planting in two growing seasons (spring, autumn). The spring growing season start from March to the end of June and the autumn growing season start from September to the end of November.

The trials of control this pest varies from chemical pesticides to biological control in addition to the bait traps (Steffens, 1983).

This pest had been studied from different research goals; one of them is the threshold temperature for development and thermal constant $(\mathrm{K})$ expressive by heat degree days which describe a relationship between the temperature with development rate

The aim of this work was to determination of the threshold temperature and the required degree days for development represent the fundamental base for prediction of phenology of the insect annually as well as integrated with the other methods specially using the insect pheromone for determination of accurate date to conduct the control means and included in the integrated pest control.

\section{Material and Methods}

A culture of adult flies of Dacus frontalis was maintained in the laboratory in plant protection Department, Agriculture College / Baghdad University, Iraq in growing season from May to December 2015. The strain was reared simultaneously in an environmental chamber maintained at $25 \pm$ $1 \mathrm{C}$ with $75 \pm 10 \%$ relative humidity under a 12:12 (L:D)-h photoperiod using natural light supplemented by artificial light. Adults were fed with enzymatic yeast hydrolysate and sugar in addition to three fruits of each cucurbit host put at the top of the three cages after $24 \mathrm{~h}$ the fruits were transferred to incubators. Although the temperature development rate curve obtained with constant temperatures. The time needed for $50 \%$ of individuals to achieve development from egg stage to adult stage was recorded at the following constant temperatures: 15 , 20,25 , and $30 \pm 1 \mathrm{C}^{\circ}$. Each experiment at 15 , 20,25 , and $30 \pm 1 \mathrm{C}$ was duplicated four times. Four incubators were used (one per temperature). Each repetition for the hosts was observed simultaneously to record the time development in each incubator. The same procedure was used for the Zucchini and The Armenian cucumber, Cucumis melo var. flexuosus, the lower development threshold ( $\mathrm{t}$; the temperature at which there is no development) was determined by extrapolation of the regression line back to the $\mathrm{x}$-axis. The threshold temperature was calculated from the regression equation ( $\mathrm{Y}=$ $\mathrm{a}+\mathrm{b} \mathrm{x})$ : between temperature and daily development rate (Arnold, 1960).

Where:

$y=$ daily rate of development

$\mathrm{x}=$ threshold temperature

$\mathrm{a}=$ intercept

$\mathrm{b}=$ regression factor (slope)

Thermal units were calculated as the reciprocal of regression coefficient as follow:

$\mathrm{K}=1 / \mathrm{b}$

Where $(b)=$ regression coefficient

(Campbell and Machauer, 1975)

Statistical analyses were performed using the life test procedure (GenStat 2009) and analysis of variance (ANOVA). ANOVA was used to analyze developmental time; 
means were compared by multiple range tests $\left(P_{-} 0.05\right)$.

\section{Results and Discussion}

\section{Development periods}

On cucumber at temperatures $15^{\circ} \mathrm{C}, 20^{\circ} \mathrm{C}$, $25^{\circ} \mathrm{C}$ and $30^{\circ} \mathrm{C}$, the development from egg to adult period was $86.85,35.1,20.04$ and 16.25 days respectively. On Armenian cucumber the periods were $85.225,33.970$, 18.666 and 15.250 respectively. On the Zucchini the periods were $82.369,33.150$, 18.888 and 15.207 respectively. The results show (table 1) significant differences of development periods of Dacus frontalis at the different temperatures and hosts, the shortest period of development to adults stage was at the $30^{\circ} \mathrm{C}$ on Zucchini reached 15.207 days and the longest period was at the $15^{\circ} \mathrm{C}$ on Cucumber.

Table.1 Development time of Dacus frontalis in deferent hosts and deferent temperature from egg to adults

\begin{tabular}{|l|l|l|l|l|}
\hline \multirow{2}{*}{$\begin{array}{l}\text { Temperature } \\
{ }^{\circ} \mathrm{C}\end{array}$} & \multicolumn{4}{|l|}{ Average of developing time (Days) } \\
\cline { 2 - 5 } & Cucumber & $\begin{array}{l}\text { The Armeniancu } \\
\text { cumber }\end{array}$ & Zucchini & Average \\
\hline 20 & 86.855 & 85.225 & 82.369 & 84.816 \\
\hline 25 & 35.139 & 33.970 & 33.150 & 34.086 \\
\hline 30 & 20.041 & 18.666 & 18.888 & 19.198 \\
\hline Average & 16.250 & 15.250 & 15.207 & 15.569 \\
\hline $\begin{array}{l}\text { L.S.D } \\
\text { P<0.05 }\end{array}$ & 39.571 & 38.278 & 38.154 & \\
& $\begin{array}{l}\text { Hosts: 0.1539 } \\
\text { Temperature: } 0.1777 \\
\text { Host } \times \text { Temp.: } 0.3078\end{array}$ \\
\hline
\end{tabular}

Fig.1 Show the relationship between the temperature and the development rate of Dacus frontalis on Zucchini

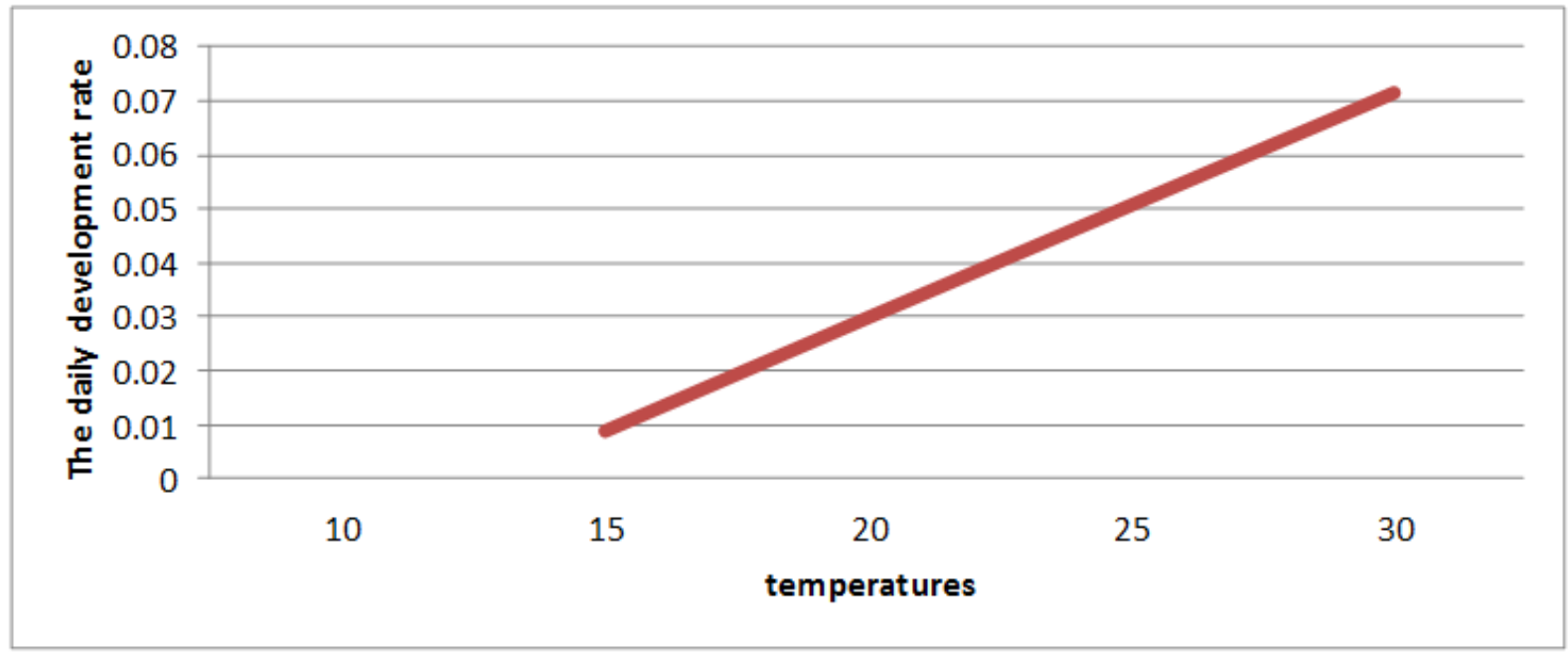


Fig.2 Show the relationship between the temperature and the development rate of Dacus frontalis on Cucumber

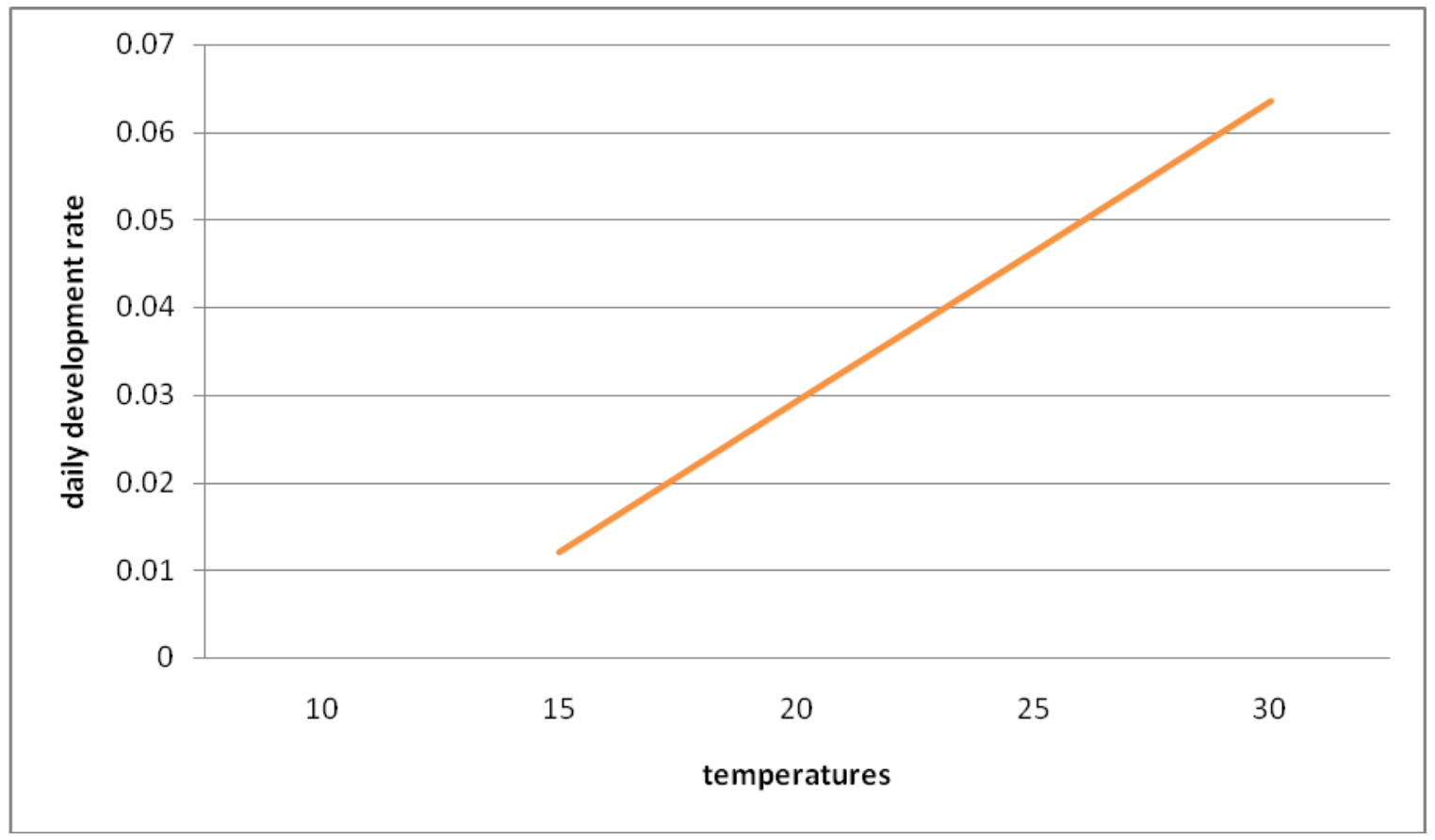

Fig.3 Show the relationship between the temperature and the development rate of Dacus frontalis on Armenian cucumber

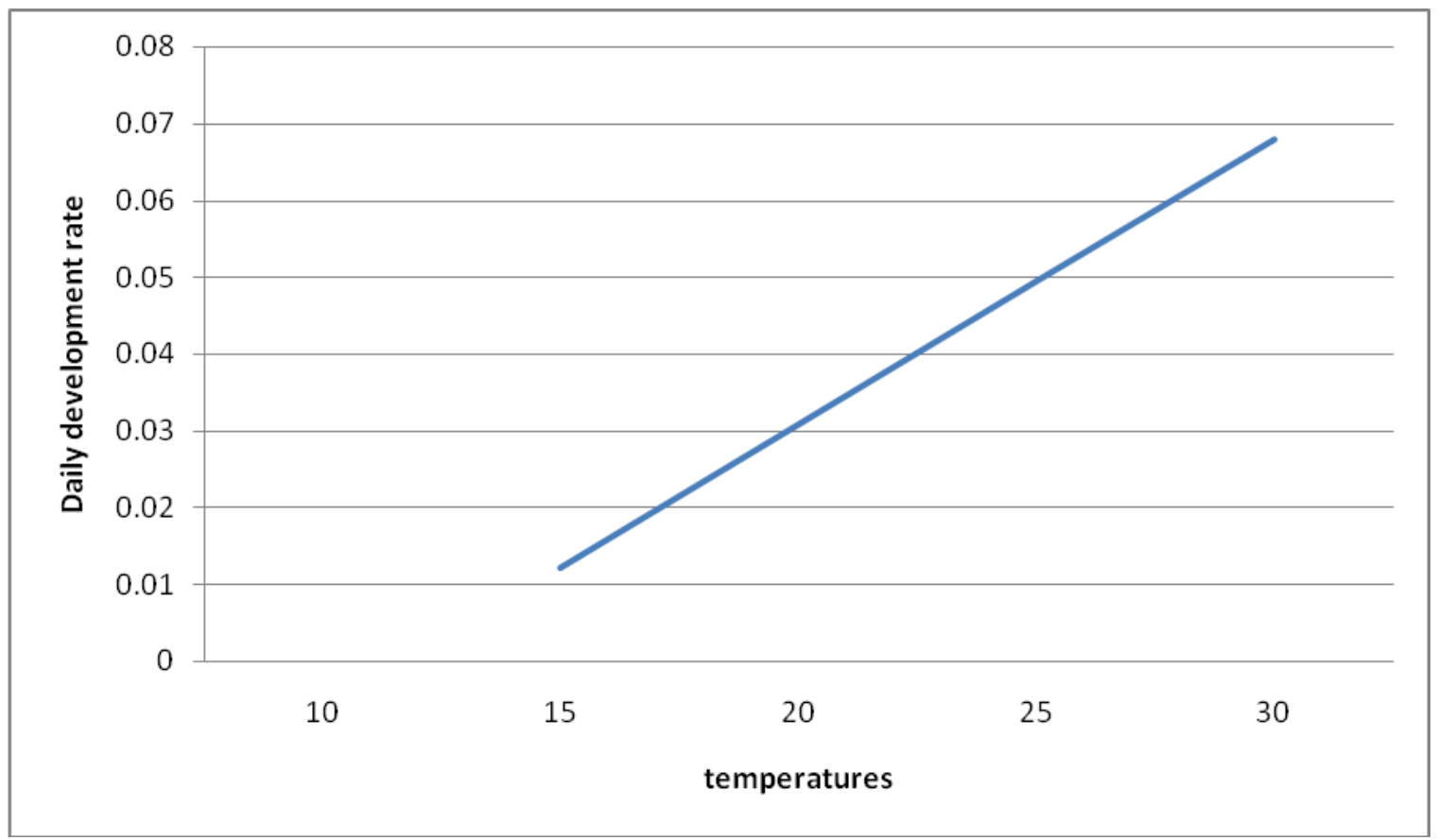

There are significant differences among development periods (DP) under different temperatures on the same host (Cucumber, Zucchini and Armenian cucumber) where 
the (DP) reached on Zucchini 15.207 days and 18.888 days under $30^{\circ} \mathrm{C}$ and $20^{\circ} \mathrm{C}$ respectively. These data can be explained that the temperature and the host plant affect the growing velocity and activity of the insect, because whenever the temperature is optimum the development is faster when the insect feed on her preferred host plant. These data is a pioneer on this insect the previous researches did not referred in any work which have devoted on Dacus frontalis.

\section{Threshold temperature}

The figures $(1,2,3)$ show the relationship between the temperature and the development rate of Dacus frontalis on the host plants Zucchini, Cucumber and American cucumber where the linear relationship and high significant correlation. The threshold temperatures were 11.7, 11.47 and 12.8 for crop Armenian cucumber, cucumber and Zucchini respectively. This is the first work on threshold temperature and development periods of $D$. frontalis. As for the required degree days summation (DDS) for insect development were 269.3, 291.6, and 240.7 degree day on the host plants referred respectively also calculated based on contrary of regression factor $(1 / b)$, up on the calculation of accumulated degree days and the temperature exist in that period, the date of insect's adults presence in the field on May as (Shawket et al., 2011) show same date of presence.

\section{References}

Arnold, C.Y. 1960. Maximum - minimum temperatures as a basis for computing heat units. Proc. Am. Sco. Hortic. Sci., 74: pp430 - 445.

AL-Jorany, Redha, S. 2013. Relative incidence of greater melon fly, Dacus frontalis Becker and Cucurbit fly,
Dacus ciliates Loew on Cucumber Cucumis sativus (L.). Mesopotamia J. Agri., Vol. (41) Suppl. (1).

Badr El-Sabah, A., et al. 2012. Temperature-Dependent Development and Degree-Days Models of the Peach Fruit Fly Bactrocera zonata(Saunders) and the Cucurbit Fly Dacus ciliatus(Loew) Int. J. Environ. Sci. Engi., (IJESE) Vol. 3: pp 85- 96.

BA-Angood, S.A.S. 1977. Control of the melon fruit fly, Dacus frontalis Becker (Diptera :Tephritidae), on cucurbits. $J$. Hort. Sci., 52: pp545- 547.

Campbell, A. and Machauer, M. 1975. Thermal constants for the development of the pea aphid and some of its parasites. Can. Ent., 107: 419-423.

Ekesi, S. and M.K. Billah. 2007. A Field Guide To the Management Press, Nairobi, Kenya. Of Economically Important Tephritid Truit Flies In Africa. ICIPE Science Press, Nairobi, Kenya.

El-Sabah, B. and A. Fetoh. 2010. Effect of fruit size on the infestation by cucurbit fly Dacus ciliatus and the melon fly Dacus frontalis. Fourth Saudi Science Conference. March 21-24. Page 254.

Gillani, W.A., Bashir, T. and Ilyas, M. 2002. Studies on population dynamics of fruit flies (Diptera: Tephritidae) in guava and nectarine orchards in Islamabad. Pak. J. Biol. Sci., 5(4): pp $452-454$.

Mahdi, Hassan Suleiman Ahmed. 2000. Environmental and lifestyle study Insecticides Dacusciliatus (Loew) (Diptera:Tephritidae) And some methods of control. A Thesis of Doctor, Plant Protection Department, College of Agriculture - University of Baghdad. Page 102.

Royer, J.E., Hancock, D.L. 2012. New distribution and lure records of 
Dacinae (Diptera: Tephritidae) from Queensland, Australia, and description of a new species of Dacus Fabricius. Aust. J. Entomol., 51: pp 239-247.

Steffens, R.J. 1983. Ecology and approach to integrated control of Dacus frontalison the Cape Verde Islands. Fruit fly of economic important, edited book, pp (632-638).
Shawkit, M.A., AL -Neamey, B., Hussian, F., Edan, L.H., Mahmood, A.R. 2011. Population Density and Biological Studies of Two Cucucrbit Flies Species:Dacus ciliates Loew and Dacus frontalis Beecker (Diptera: Tephritidae. J. Madinatalilm Univ., Vol (3) pp(71-75).

\section{How to cite this article:}

Hasanain Yosuf Al-Shalchi and Redha S. Al Jorany. 2016. Temperature Threshold and Thermal Constant of Dacus frontalis (Beker) (Order: Diptera: Tephritidae) on Three Cucurbit Hosts. Int.J.Curr.Microbiol.App.Sci. 5(9): 483-488. doi: http://dx.doi.org/10.20546/ijcmas.2016.509.053 